\title{
LA FÁBRICA DE DOBLE HOJA EN MADRID, UN SIGLO DE CERRAMIENTO MODERNO
}

\author{
(DOUBLE MASONRY WALLS IN MADRID, A CENTURY OF MODERN ENCLOSURES)
}

Juan Manuel Ros García. Dr. Arquitecto.

Profesor Titular de la Escuela Politécnica Superior. Universidad San Pablo CEU.

Fecha de recepción: 2-I-05

ESPAÑA

$876-11$

\section{RESUMEN}

El presente trabajo se centra en el desarrollo y la implantación del sistema de doble hoja en los cerramientos de fábrica dentro de la arquitectura residencial madrileña a lo largo de los dos primeros tercios del siglo XX. De una parte, se aborda la cuestión desde un campo de comprensión histórica comparada, en la que pueda llegarse a definir una conciencia clara de evolución o de impulso de progreso a través de ciertas y reconocidas manifestaciones arquitectónicas que sucedieron paralelamente con el periodo de revolución técnica en Europa y su más lenta penetración en nuestro país, centrando el análisis en su localización madrileña. De otra, se consideran los sistemas y métodos constructivos generales aplicados a distintas tipologías y determinados ejemplos notables, con el fin de asociarlos a posibles modos de innovación técnica en los procesos expansivos de la vivienda de calidad arquitectónica, a la que se atribuye una coherencia material y formal. La incorporación de los materiales aislantes a la construcción de cerramientos y el desarrollo de la cámara de aire con relación a la tradición heredada y el incipiente nuevo lenguaje de los años treinta. Asimismo contemplar, con el paréntesis que supuso la guerra civil, la interrupción de la tendencia progresista iniciada con anterioridad y, a partir de la misma, la existencia obligada de reconstrucción, materializada en una política urgente de vivienda mezclada con un espiritu de triunfalismo magnificado y determinado por la arquitectura oficial. El estudio y clasificación de los distintos tipos de sistemas constructivos en los que cobra fuerza la presencia del cerramiento de doble hoja, la que se refiere a la diferenciación de capas de distintos materiales como solución compositiva moderna cada vez más adoptada por los modelos contemporáneos, y que nos conducirá, poco a poco, a la estandarización de los cerramientos en la vivienda urbana de los años cincuenta. La influencia realmente determinante que ejerció la reglamentación normativa aplicada a la protección pública de las viviendas, especialmente a partir de 1940, que contempla el análisis del comportamiento higrotérmico de los cerramientos como niveles mínimos exigibles de calidad y la realización de los documentos gráficos precisos en el dimensionamiento del proyecto constructivo, como factor relevante en el desarrollo del sistema. De esta manera se consigue abrir una posibilidad de influencia técnica en la producción arquitectónica que tiene que ver con los planteamientos y el avance de las

\section{SUMMARY}

The present paper describes the development and generalized use of the double or hollow wall system in masonry enclosures in Madrilenian residential architecture in the first two thirds of the twentieth century. The question is addressed, on the one hand, from the standpoint of comparative history, in which a clear awareness of evolutionary progress can be defined through certain recognizable architectural tendencies that arose during the technological revolution taking place in Europe and somewhat later in our country; in this regard, the analysis focuses on developments in Madrid. On the other hand, consideration is given to the general construction systems and methods applied to different typologies and representative examples associated with possible modes of technical innovation in the expansive processes involved in housing of high architectural quality, characterized by material and formal consistency. The inclusion of insulation materials in wall construction and the development of the air chamber are likewise dealt with in the context of inherited tradition and the incipient new language developed in the nineteen thirties. The discussion also reflects on the parenthesis imposed by the Civil War, the interruption of the progressive trend begun prior to and continued after that conflict and the need to rebuild which materialized in an emergency housing policy mixed with a spirit of euphoria magnified and defined by the official architectural establishment. The different types of construction systems where double walls became increasingly popular are studied and classified, differentiated on the grounds of the materials used - a modern compositional solution adopted with growing frequency in contemporary models, that would gradually lead to the standardization of such enclosures in urban housing in the nineteen fifties. Also considered is the truly determining influence, particularly beginning in the nineteen forties, of the legislation applied to publicly financed housing, which called for analysis of the hygrothermal performance of enclosures as a standard requirement. The drafting of all necessary drawings in the dimensioning of construction designs likewise proved to be a relevant factor in system development. This serves as an introduction to the possible influence of technical concerns on architectural production that has to do with the approach to and progress in the construction solutions 
soluciones constructivas empleadas en cada caso, para proponer una presentación complementaria fundamental en la historia de los estilos en un periodo de lentos, dificultosos pero inevitables cambios acaecidos en la arquitectura con alcance nacional de, aproximadamente, la primera mitad del siglo $X X$.

Un cambio social y politico en la historia no siempre representa, en nuestro caso, una diferencia en los planteamientos técnico-constructivos de las soluciones adoptadas. Realmente interesante en el objetivo principal del presente trabajo, es comprobar el camino contrario, esto es, el grado de influencia de determinados condicionantes materiales de soluciones constructivas de los cerramientos adoptadas por arquitectos de calidad ante los compromisos renovadores de una nueva arquitectura y su resultado final de progreso.

Es un proceso de cambio continuado que lleva, bajo un punto de vista global, desde la ambivalencia o eclecticismo formal de variadas alternativas historicistas y demás referencias académicas, hasta la depuración compositiva y una pretendida simplificación dialéctica de rasgos modernos y europeizantes. Esquema conceptual reiterado, con recorrido histórico de ida y vuelta, que, sin embargo, no viene acompañado necesariamente por la normal transformación en la técnica y el papel del cerramiento. Por lo que se escribirá una historia paralela, la historia concreta de los cerramientos, de los usos técnicos aplicados a la arquitectura teórica de prestigio centrada en la producción madrileña de, aproximadamente, los primeros sesenta años del siglo XX. Y, finalmente, referir las conclusiones a la formación, en cada caso, de una tendencia técnica en el uso de sistemas de organización compositiva del cerramiento estudiado y del conjunto de ellos, definir la existencia de aplicación de una determinada solución constructiva con relación a una exigencia interna de la arquitectura, como pudiera ser el carácter representativo y social de la obra, sus recursos económicos, el cumplimiento de una normativa legislativa, la adecuación a un programa especifico, el creciente nivel de satisfacción social del espacio residencial, los cambios que significaron la aparición de nuevas tipologías estructurales, la presencia del edificio como repercusión urbanística en la organización de la ciudad y sus nuevos desarrollos, etc... Así, un cambio real dentro del proceso de modernidad ideológica se ve favorecido en su propia coherencia interna desde la racionalización constructiva generalizada de los avances técnicos que la hicieron posible, siendo objeto de este breve artículo ponerlos de manifiesto y valorarlos, en cada caso, de manera experimental. deployed in each case, to propose an essential supplementary presentation in the history of styles in the period of slow, difficult but inevitable change in nation-wide architecture covering approximately the first half of the twentieth century.

Social and political change during a given historic period does not always mean a difference, in our case, in the technical approach taken to the construction solutions adopted. What is actually interesting in this paper is the return route, i.e., the influence of certain material conditioning factors on the constructions solutions adopted for enclosures by architects concerned with quality in the light of the reformist commitments of the new architecture and the end result in terms of progress.

Globally viewed, this process of ongoing change leads from the ambivalence or formal eclecticism of a variety of historicist alternatives and other academic references to compositional refinement and intentional dialectic simplification, of modern and "European" inspiration. This reiterated conceptual scheme, which ran a full historic circle, was not necessarily accompanied by any logical change in the role of or techniques for building enclosures. All the foregoing provides the backdrop for the writing of a parallel history, the specific history of enclosures, the technical practice applied in theoretical architecture of prestige, in which the focus is on Madrilenian production in approximately the first sixty years of the twentieth century. Finally, the conclusions highlight the generation of trends in the use of technical systems for the compositional organization of each enclosure studied and all of them taken together, identifying the existence of the application of certain construction solutions related to internal architectural requirements, such as the representative and social nature of the work, economic resources available, compliance with the existing legislation, adaptation to a specific programme, growing importance of social satisfaction in residential endeavours, changes introduced with the appearance of new structural typologies, presence of buildings as the urban repercussion on city planning and new developments, and so on Hence, the internal consistency of a real change in the process of ideological modernity was favoured by the generalized constructional rationalization of the technical progress that made it possible; the purpose of this brief article is to discuss and evaluate each case in experimental terms.

\section{INTRODUCCIÓN}

No es exagerado afirmar que la historia de la construcción durante la mayor parte del siglo XX, no sólo en España, y no sólo en Madrid, se centra en la sucesión de factores que permitieron el desarrollo, hacia un modelo técnico estandarizable, del sistema de doble hoja en los cerramientos de fábrica, el que se refiere a la diferenciación de capas de distintos materiales como solución compositiva moderna cada vez más adoptada por los modelos de aquella arquitectura contemporánea realizada aproximadamente hasta 1960 .
Su implantación es el resultado de ciertos acontecimientos que tienen que ver con el período de revolución de los sistemas constructivos tradicionales y la nueva realidad material asociada a los tipos estructurales. De igual manera, la influencia realmente determinante que ejerció la reglamentación, normativa aplicada, concretamente, a la protección pública de las viviendas $\mathrm{y}$, especialmente, a partir de 1940, que contemplaba el análisis del comportamiento higrotérmico de los cerramientos como niveles mínimos exigibles de calidad y la realización de los documentos gráficos precisos en el dimensionamiento del proyecto 
constructivo, es un hecho decisivo en la evolución de las soluciones de doble hoja. Especialmente interesante también es comprobar el grado de influencia de determinados condicionantes materiales de soluciones constructivas de los cerramientos adoptadas por arquitectos de calidad ante los compromisos renovadores de una nueva arquitectura y su resultado final de progreso. Es un proceso de cambio continuado que lleva, bajo un punto de vista global, desde la ambivalencia o eclecticismo formal de variadas alternativas historicistas y demás referencias académicas de los comienzos, hasta la depuración compositiva y una pretendida simplificación dialéctica de rasgos modernos y europeizantes. La interrupción, con la guerra civil, de la tendencia progresista iniciada con anterioridad $\mathrm{y}$, a partir de la misma, la existencia obligada de reconstrucción materializada en una política urgente de vivienda mezclada con un espíritu de triunfalismo magnificado y determinado por la arquitectura oficial, implicaría una revisión forzosa del sistema desarrollado hasta entonces que lo elevaría definitivamente a la categoría de tipo.

Un cambio social y político en la historia no siempre representa, en nuestro, caso una diferencia en los planteamientos técnico-constructivos de las soluciones adoptadas y, por tanto, no viene acompañado, ni exclusiva ni necesariamente, por la normal transformación en la técnica ni en la función propia del cerramiento. Por ello, se hace vital definir la existencia o no de la aplicación de una determinada solución constructiva con relación a una exigencia interna de la arquitectura, como pudiera ser el carácter representativo y social de la obra, sus recursos económicos, el cumplimiento de una normativa legislativa, la adecuación a un programa específico, el creciente nivel de satisfacción social del espacio construido, los cambios que significaron la aparición de nuevas tipologías estructurales y materiales especializados, la presencia del edificio como repercusión urbanística en la organización de la ciudad, sus nuevos desarrollos, etc..., desde el marco preponderante ejercido por Madrid. Al mismo tiempo, definirla con relación a exigencias externas de la arquitectura, como: cambios históricos, políticos y avances socioculturales. Así, un cambio real dentro del proceso de modernidad ideológica es favorecido en su propia coherencia interna desde la racionalización constructiva generalizada de los avances técnicos que la hicieron posible y se hace preciso, de esta forma, ponerlos de manifiesto, valorarlos en cada caso de manera pragmática y sugerir entonces una historia paralela, la definida por la materialización de las secciones constructivas de sus cerramientos.

\section{LA DEFINICIÓN DE UN NUEVO TIPO CONS- TRUCTIVO}

Desde una perspectiva histórica, la fecha de 1910, puede considerarse punto de inflexión de tendencias. Por un lado, se produce la máxima intensidad en la inercia academicista decimonónica en cualquiera de sus versiones y, por otro, el principio de los planteamientos que conducirían lentamente a exigir una mayor sobriedad y sencillez en la obra arquitectónica dentro de un anhelado espíritu reformista. De un arquitecto preocupado por resolver aspectos formales, dejando de lado la renovación constructiva, o empeñado en cuestiones rezagadas de búsqueda del estilo representativo españolista, se dará paso a otro tipo de arquitecto, comprometido en un proceso de racionalización y coherencia interna. De manera incipiente, se revalorizarán los modelos de la arquitectura popular y se desarrollarían los regionalismos modernizados. Bajo un punto de vista legislativo, en 1911 se promulga la Primera Ley de Casas Baratas, que, además de representar el primer precedente de regulación técnica de aplicación a la construcción pública de viviendas para las clases más modestas incorporando los modernos criterios higienistas, supuso un impulso para el sector de la construcción. Su influencia se deja notar en los sucesivos textos normativos, los de la Segunda y Tercera Ley de Casas Baratas de 1921 y 1924, la Ley de 1925 de Casas Económicas para las Clases Medias, la Ley para Funcionarios del Estado de 1927 y la conocida "Ley Salmón" de 1935, manteniéndose similares criterios respecto a garantizar las condiciones básicas de salubridad y protección frente a la humedad en sus cerramientos, dejando las soluciones y precauciones correspondientes al criterio técnico del arquitecto del proyecto. Así, sin detallar en ningún caso soluciones constructivas el Reglamento de Condiciones Técnicas de Construcción de 1922 fija niveles mínimos de calidad relacionados con niveles suficientes de iluminación y ventilación. Para ello se pide, junto con la memoria, escrita una documentación gráfica a escala de $1 / 100^{1}$. Hasta entonces y sin duda por la repercusión de los textos normativos (como el Art.116 del mencionado Reglamento de 1922) se había impuesto la razón de no considerarse objeto necesario en la definición del proyecto todos los detalles propios dibujados de las soluciones constructivas de los cerramientos, que, por otra parte, y salvo casos muy específicos, se tratarían con los procedimientos habituales y contrastados por la buena tradición. En este sentido, el arquitecto Gustavo Fernández Balbuena afirma, en 1925, de igual manera: $<<\ldots$ en los dibujos está latente un deliberado propósito de dejar apenas esbozadas las ideas, para que, más tarde artífices y obreros las continúen y acaben según la costumbre y el hábito local >>.

Asimismo, el 30 de marzo de 1911 se inician las obras que significarían la presencia de una nueva técnica en Madrid, la primera estructura porticada de hormigón armado en un edificio residencial, el Hotel Palace. Construido sólo en 18 meses, adoptaría el método empleado con gran éxito en Bélgica por el ingeniero Monnoyer, consiguiendo en 1912 el primer premio del Ayuntamiento de Madrid al edificio mejor construido. El primer gran ejemplo significativo en el que la nueva alternativa de sustentación de entramados reticulados de hormigón armado, mejoraría 


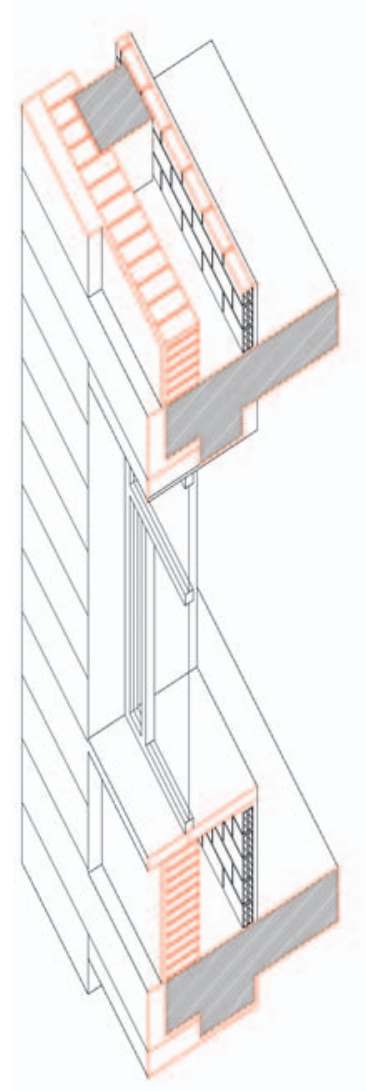

Hotel Palace. Ferres y Puig, Monnoyer, Alvarez Naya, 1910-12

en coste y rapidez las ya conocidas con cierta anterioridad, estructuras metálicas. Como consecuencia de su desarrollo en todo el tejido urbano madrileño de los ensanches o más allá de las Rondas, surgen numerosos ejemplos de cerramientos construidos en los que se hace inevitable la presencia de un gran espacio libre intermedio como recurso de ocultamiento de pilares en fachada, así como la deseada norma de regularización del paramento interior. La sección de los pilares en línea de fachada, condicionaría el dimensionamiento de las primeras cámaras de aire que resultaron ser, en su mayoría, muy generosas (en el caso del Hotel Palace, de $32 \mathrm{~cm}$ ).

Con lo que las primeras estructuras porticadas no significaron la reducción del espesor de los cerramientos, sino más bien una notoria contradicción: la presencia de muros de gran superficie ocupada en planta pero carentes de función estructural. A pesar de ello es posible hablar ya de una técnica nueva de cerramientos de doble plementería, asociada y condicionada al avance de las tipologías de pórtico, esto es, el sistema de doble hoja.

Sin embargo, aunque con el uso de las estructuras porticadas se va reduciendo la carga historicista en la composición arquitectónica de etapas anteriores, la inercia constructiva tradicional hizo costosa la aplicación de las nuevas posibilidades técnicas ${ }^{2}$, produciendo un efecto de indecisión que facilitó el desarrollo del eclecticismo como estilo provisional, sin aprovechar la nueva expresividad de este tipo de estructuras. Un claro ejemplo de este fenómeno se puede encontrar en el edificio Le Phenix que realizó Secundino Zuazo en la calle Velázquez entre 1928 y 1931, edificio de estructura porticada con muros extremadamente gruesos no macizos, que reflejaban un carácter tectónico que ya no correspondía constructivamente, pero que confería cierto concepto de establecida e irrenunciable calidad. Ejemplo de construcción de apariencia masiva en su composición arquitectónica, de ornamentación superpuesta de fuentes diversas, que nos remite todavía a los antiguos criterios de edificación decimonónicos, justo en el mismo momento en que se estaban llevando a cabo en Europa los grandes experimentos constructivos con nuevos materiales, fruto de una incipiente industria moderna de la construcción, aplicados a la vivienda so$\mathrm{cial}^{3}$. Reduciéndo el problema a términos de sistemas constructivos capaces de soportar el carácter económico del modelo de vivienda de bajo coste, se introduce de forma decidida la técnica diferenciada de hojas en los cerramientos como pauta de renovación para los modelos constructivos en el desarrollo de soluciones en serie más eficientes. En nuestro país, ello no hubiera sido posible sin el avance en el conocimiento y difusión de las nuevas teorías de intercambio energético que demostrarían, gracias a los nuevos materiales aislantes, la conservación de las condiciones de habitabilidad interior a pesar de la gran consecuencia espacial y apuesta constructiva: ¡¡la reducción efectiva de espesores en el cerramiento!! La acogida de la nueva técnica se argumenta, por una parte, como necesaria desde una opción moderna. Así, Amós Salvador escribe, en 1929, con ocasión de la celebración en septiembre de ese año del II Congreso CIAM de Frankfurt sobre la Vivienda Mínima, y mientras cuestionaba la conveniencia legislativa de la entonces vigente Ley de Casas Baratas: $<<$ Habrá que tener en cuenta que en casi toda España...hay una separación importantísima entre temperaturas extremas. Esto plantea el problema del aislamiento térmico a primera vista incompatible con la economía, pues parece aconsejar el empleo de grandes muros, ..., sin embargo el empleo de ladrillo hueco y la disposición de cámaras de aire aisladoras, juntamente con la colocación de tabiques de materiales malos conductores puede contribuir a resolverlo de un modo sencillo $>>^{4}$. Curiosamente, en representación de la arquitectura española a dicho congreso es seleccionada la propuesta ganadora del Primer Concurso Nacional de Vivienda Mínima en España, promovido en 1929 por García Mercadal tras la experiencia de la Deutscher Werkbund en la Colonia Weissenhoff para modelos residenciales de bajo coste. En la propuesta, del arquitecto Rivas Eulate, se puede apreciar la solución constructiva de doble hoja dibujada en la planta de su cerramiento, sin duda señal inequívoca de modernidad. Habría que esperar a 1931 con el Edificio Coliseum (C.Fdez.-Shaw Iturralde y P. Muguruza Otano) 
para hacerse consciente en el proyecto dibujado, la función constructiva de la cámara, en este caso con espesor de $8 \mathrm{~cm}$. A partir de este momento es frecuente encontrar la presencia de las grandes cámaras como espacio separador entre las dos hojas del cerramiento. Luis Gutiérrez Soto las aplicaría sistemáticamente en esta época como principio regulador material de sus estructuras principales, y son varios los ejemplos aparte, en los que se introduce la cámara en los cerramientos de acuerdo a la orientación más o menos expuesta de los mismos. Por otra parte y al mismo tiempo, la nueva técnica se ajustaba a las teorías europeas de racionalización constructiva o a la Ley de Economía. Así, en la revista AC se afirma: $<<$ Se conocen nuevos procedimientos y materiales de construcción de uso universal. Debemos adoptarlos. Las necesidades económicas exigen la rápidez sin olvidar la perfección. La industria puede resolverlo produciendo elementos-tipo fabricados en serie $>>5$. Aunque la solución de doble hoja estaba implantada desde hacía tiempo en zonas sobre todo de climas húmedos según la tradición del cavity wall anglosajón, desarrollado durante todo el siglo XIX, el sistema se fue extendiendo como una nueva forma de construcción más eficaz y económica dentro del avance higienista de la época a la que se incorporaba el recurso de aireación integrada para cerramientos cargados. A lo largo sobre todo de la década de los años veinte, los maestros del Movimiento Moderno, en su aspiración purista por las geometrías elementales, insistirán permanentemente en establecer una relación de continuidad material entre estructuras porticadas y cerramientos diferenciados por capas, como resultado de aplicar a la razón constructiva de la forma los nuevos métodos técnicos y productivos. Intento, prematura y materialmente fallido por basar en una descoordinación dimensional un principio estético. Desde 1908, en nuestro país, con la publicación en $L a$ Construcción Moderna de un artículo sobre los ladrillos de corcho $^{6}$, y hasta 1940 aproximadamente, se abre un proceso de difusión en distintas revistas profesionales sobre la conveniencia y economía de incorporar los nuevos materiales aislantes a la construcción de cerramientos de fábrica, que permitió abrir una vía de investigación con soluciones prácticas a la composición de fachadas heterogéneas, a la progresiva reducción de espesores y así integrarse en las corrientes del economicismo industrial y tecnológico. Destaca en 1926 la presentación por parte del ingeniero M. Bastos en la revista Arquitectura ${ }^{7}$, de un método analítico de transmisión de calor, análogo conceptualmente al utilizado en la actualidad. En 1927, un año más tarde a esta publicación, encontramos un primer ejemplo singular, pionero en la utilización del sistema de doble hoja con aislamiento incorporado: la Casa del Marqués de Villora en la calle Serrano de Rafael Bergamín. Se trata de un caso excepcional, aunque no para su autor, en el que se mejora el rendimiento de los muros de carga con pulgada y media de plancha de corcho aglomerado aplicado sobre una capa de alquitrán en caliente sobre el trasdós de la primera hoja del cerramiento,

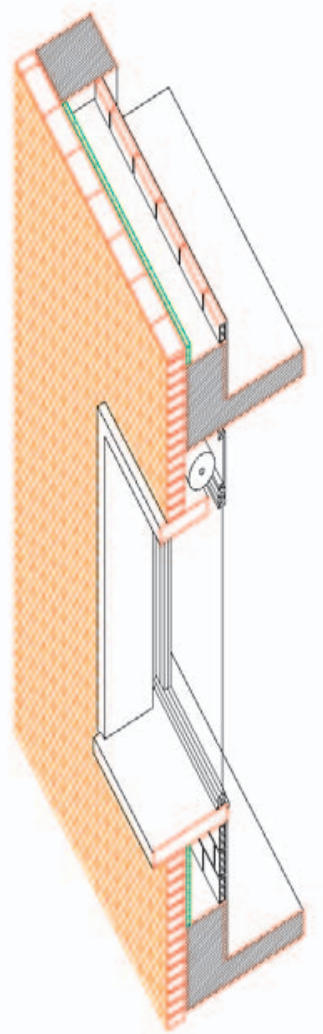

Residencia Universitaria de Estudiantes. Luis Lacasa, 1932-36.

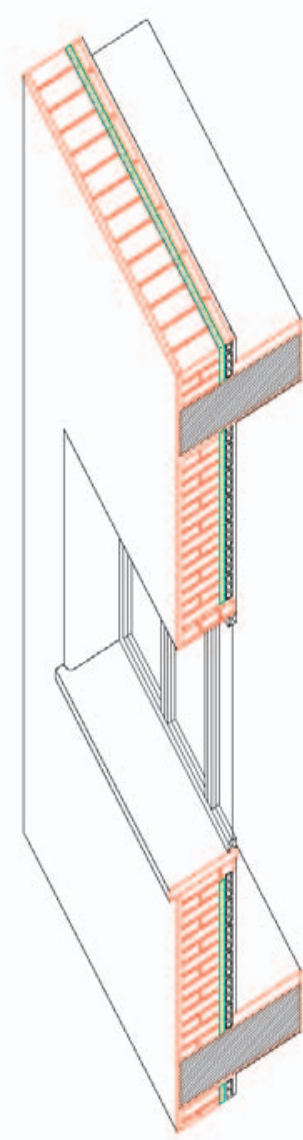

Colonia El Viso. Rafael Bergamín Gutiérrez. 1933-1936 cámara de aire de $7 \mathrm{~cm}$ y tabique sencillo con ladrillo hueco al interior, espesor total de $42 \mathrm{~cm}$ cuyo coeficiente $\mathrm{K}$ de transmisión térmica en su parte ciega se reduce hasta $0,595 \mathrm{Kcal} / \mathrm{hm}^{2}{ }^{\circ} \mathrm{C}$. A partir de ella escribiría Bergamín: $<<$ Con la adopción de esta protección en las cinco grandes superficies de radiación de una casa aislada y la reducción del tamaño de los huecos de fachada, se hace un ensayo de aislamiento cuyos resultados se apreciarán y estudiarán en lo sucesivo $>>8$. Habría que esperar hasta 1932 para encontrar una aplicación similar, aunque ahora en un cerramiento no cargado: la Residencia Universitaria de Estudiante,s de Luis Lacasa. Sin embargo en este caso, la cámara de aire se vuelve a dimensionar de acuerdo a los criterios mencionados con anterioridad: ocultar la presencia al interior de los elementos estructurales, regularizando el paramento. El grueso pilar de hormigón obliga una cámara excesiva de $22 \mathrm{~cm}$ por detrás de la primera hoja de medio pie y una pulgada de aislamiento de plancha de corcho en su trasdós. Un tabique de hueco sencillo busca la cara interior del pilar hasta los $41 \mathrm{~cm}$ de espesor total con un coeficiente $\mathrm{K}$ de $0,674 \mathrm{Kcal} / \mathrm{hm}^{2}{ }^{\circ} \mathrm{C}$.

Si dicho ejemplo representa la tipificación del sistema de doble hoja dentro de la construcción de anteguerra, las Casas Gemelas, de Manuel de Cabanyes en 1935, de nue- 
vo en la calle Serrano de Madrid, significan la solución constructiva de cerramiento más avanzada, precursora de la futura estandarización de los años cincuenta. Se deja a un lado la excesiva dimensión en planta de la cámara de aire (de dudosa eficacia térmica) para acercarse a los valores económicos de ocupación y relación proporcionada con los elementos estructurales. En este caso, según la memoria constructiva del proyecto: $<<$ La estructura general del edificio se ha proyectado, como consecuencia de un estudio de mejor aprovechamiento del solar, en acero laminado, por la consiguiente disminución de espesores de los muros, teniendo especial cuidado de asegurar, no obstante, el debido aislamiento del medio ambiente $>>$. La solución consiste en una primera hoja de fábrica al descubierto de media asta o chapada con losas de Novelda, en cuyo caso esta formada por tabicón de ladrillo hueco en posición de seis celdas, plancha de corcho aglomerado de una pulgada de grueso, cámara de aire de $6 \mathrm{~cm}$ y tabique interior de ladrillo hueco sencillo recogiendo los pilares metálicos. Todo se ha estudiado de manera que, $<<n o$ obstante su reducido espesor y ligereza de peso, aseguren un aislamiento que oscila entre el que proporcionaría un muro macizo de $1,50 \mathrm{~m}$ a $0,50 \mathrm{~m}$ de grueso $>>{ }^{10}$. En el caso de estructuras mixtas, la solución de cerramiento multicapa también se puede encontrar. En 1933-36, la innovadora construcción de la Colonia El Viso, amparada por la todavía vigente Ley de Casas Baratas, y con un planteamiento de seriación material y abaratamiento de recursos, resuelve (de nuevo de la mano de Rafael Bergamín) un cerramiento de carga a base de un pie de ladrillo sílicocalcáreo, una plancha de corcho aglomerado en su trasdós de una pulgada, al que se adosa sin cámara interpuesta una hoja interior de ladrillo sencillo, espesor total de $36 \mathrm{~cm}$, un coeficiente de transmisión $\mathrm{K}$ de $0,670 \mathrm{Kcal} / \mathrm{hm}^{2}{ }^{\circ} \mathrm{C}$ y estructura de perfilería metálica comercial en su crujía central de pilares.

La realidad constructiva predominante (de auge en el protagonismo de las nuevas tipologías estructurales y el empuje tecnológico de los materiales aislantes incorporados a los cerramientos), no era sino la manifestación de un proceso de racionalización, que decantado, (una vez asumidas las influencias foráneas, hacia el denominado expresionismo funcionalizado característico de una primera generación progresista de arquitectos, la denominada Generación del 25), establecerá desde Madrid, el marco adecuado de asimilación técnica para la irrupción de la ortodoxia purista del Movimiento Moderno esta vez a cargo principalmente de los arquitectos del Grupo Este del GATEPAC, y cuyo recorrido se extinguiría en el paréntesis de la contienda civil.

Como reacción a esta tendencia, propia de la vanguardia constructiva de los años treinta, y dentro del nuevo y competitivo mercado de la construcción, surge con fuerza a pesar del encarecimiento de la mano de obra cualificada, un ejemplo notable y promocional del uso del ladrillo en cantidades masivas como cerramiento cargado: la Casa de las Flores (1930-32). En su construcción, Zuazo aprovechó al límite de sus posibilidades el material y aplicó de forma magistral todas las técnicas inherentes a la fábrica en ladrillo, sintiéndose heredero de la sólida tradición madrileña con ladrillo que partiendo de las influencias decimonónicas más históricas, pasa por la maestria de un López Salaberry, el oficio sobrio de un Antonio Flórez y el modelo próximo de un Gustavo Fernández Balbuena. Zuazo consigue mediante una buena disposición geométrica de la estereotomía del material suplir la necesidad de incorporar estructuras porticadas, manteniendo las buenas prestaciones higrotérmicas del muro de carga de pie y medio sin necesidad de incorporar otras capas que se encarguen de dicho aislamiento. A pesar de la calidad arquitectónica obtenida, el mismo Zuazo comentaría: "Los arquitectos madrileños, sin embargo, no parecieron muy interesados por este camino" ". Hay que señalar también en este caso la circunstancia realmente importante y significativa que supuso su publicación en la revista $A r-$ quitectura $\mathrm{n}^{\circ} 163$ (1933), como antecedente histórico del detalle constructivo aplicado a un cerramiento tipo, formando parte de la definición del proyecto y por primera vez en una sección a la escala de 1/20.

Un poco posterior a la realización de la Casa de las Flores, en 1934, a otra escala de intervención, pero con similar procedimiento constructivo de fábrica resistente, sorprende por su excepcionalidad de caso aislado, el cavity wall de la doble vivienda unifamiliar que Gabriel de la Torriente proyecta en San Lorenzo de El Escorial. Ejecutada en el breve plazo de cuatro meses a pesar de las continuas huelgas obreras, se trata de una solución rigurosamente basada en la ventilación de la cámara según el modelo anglosajón. Destacan las piezas de traba de "hierro para atado de fábrica" de $20 \mathrm{~cm}$ y su disposición cada cuatro hiladas. Cámara de aire (denominada en su memoria: "cavidad") de $6 \mathrm{~cm}$, dos medios pie de hojas, siendo la primera hoja exterior de "recocho", y la hoja interior de estabilidad para apoyo de forjado. En la intención de su autor está presente el comportamiento higrotérmico del cerramiento y así lo describe:

$<<$ En estas condiciones se optó por hacer una fábrica de ladrillo al descubierto de $28 \mathrm{~cm}$ de espesor, con cámara de aire perfectamente ventilada, cuyas condiciones de aislamiento térmico equivalen a una fábrica de mampostería de dos veces y media su espesor $>>12$.

Aunque la tendencia constructiva en la técnica de cerramientos durante la década de los años treinta, se orientaba ya de forma decidida hacia el control térmico de las distintas variables según la diferenciación de capas, se observa no obstante con fuerza un desarrollo importante de las soluciones estructurales de tipo mixto, con entramado interior y cerramiento de carga. Este hecho hay que interpretarlo como respuesta de conveniencia (o segura) 

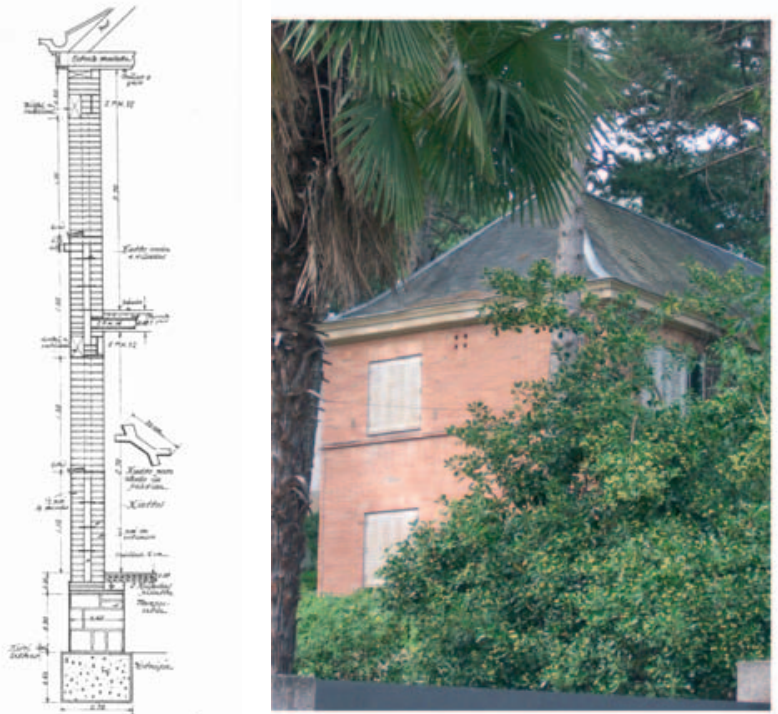

Vivienda en El Escorial. G. de la Torriente.1934.

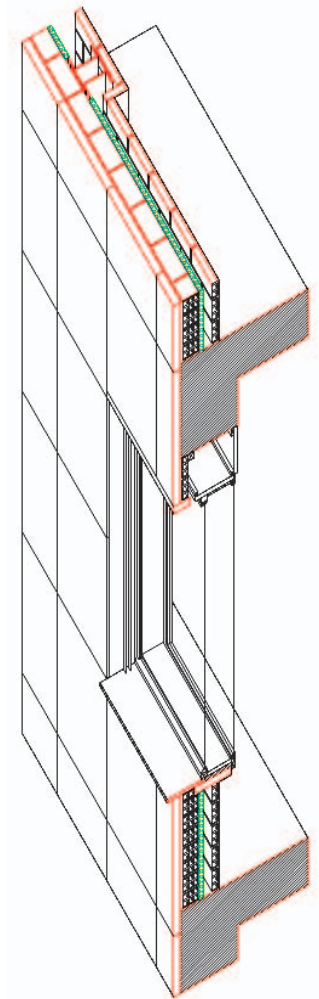

Casas Gemelas. Manuel de Cabanyes Mata, 1935.

que adoptaron los arquitectos de aquella época ante las ventajas de utilidad y eficacia, por una parte, que permitía la técnica de los nuevos entramados estructurales (mayor libertad y espacio de distribución interior, rapidez constructiva, economía...) y, por otra, el todavía desconocimiento generalizado de aplicación de los métodos selectivos del heterogéneo cerramiento moderno. Destacan en esta línea diversas actuaciones como las más de 1.500 vi-

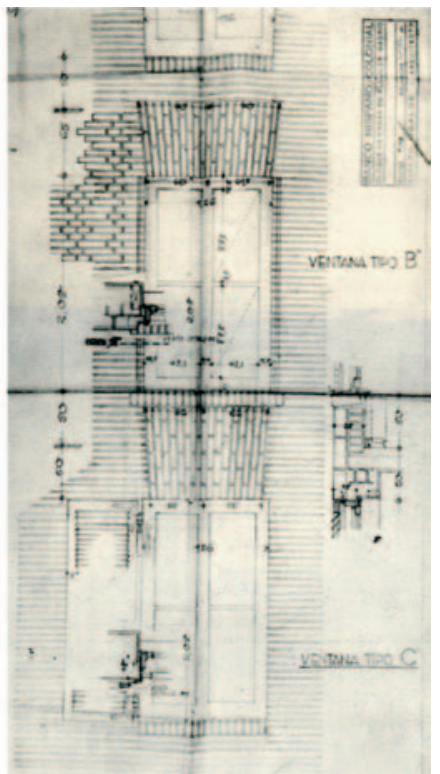

Casa de Las Flores. Secundino Zuazo,1930-32.

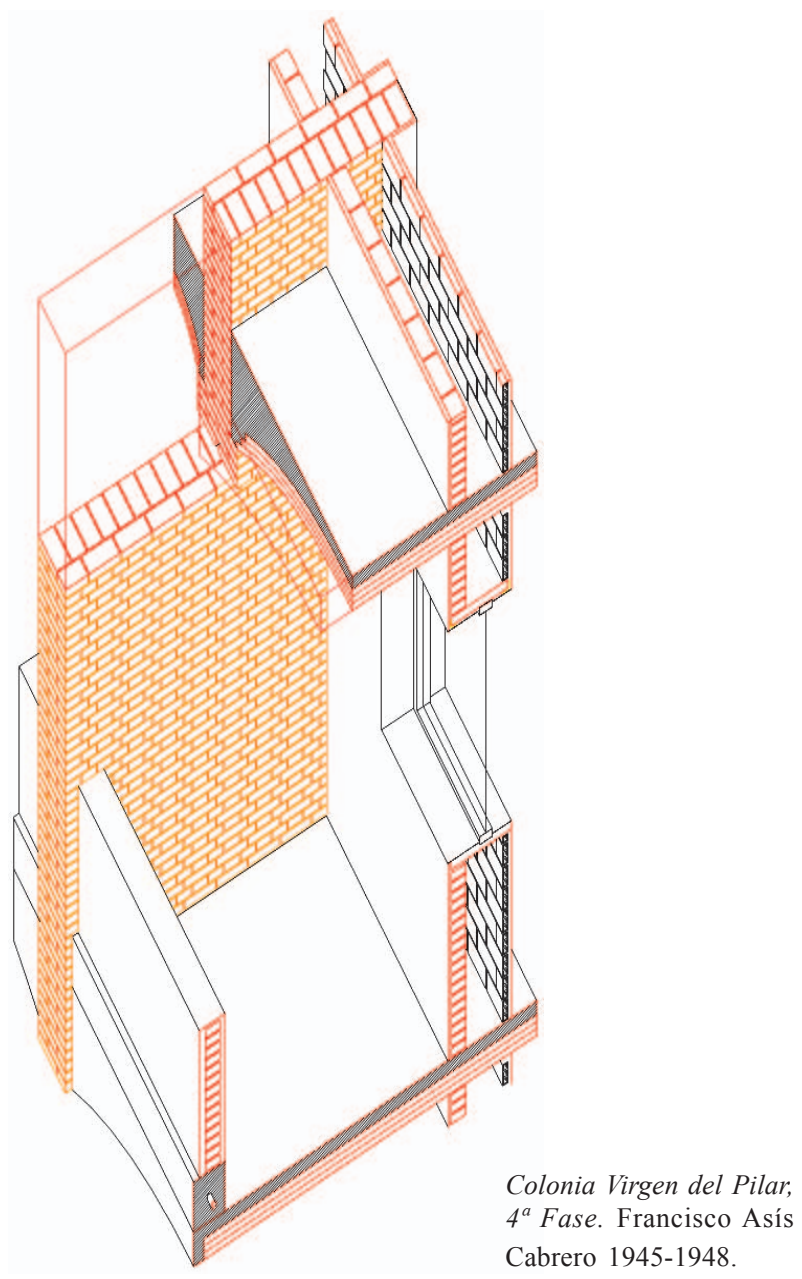

viendas de la Colonia del Pico del Pañuelo para la Sociedad Constructora y Beneficiaria de Casas Baratas, en una tipología plurifamiliar innovadora (F. de Escondrillas, 
1927-30) o los edificios de la calle Vallehermoso para la Sociedad Ajo y Morales (A. Laciana, 1934-35), dentro de la característica elementalidad constructiva de la llamada Ley Salmón, que permitió difundir una versión domesticada de una pretendida audacia racionalista al tiempo que fomentar una dañada industria productiva.

\section{LA PÉRDIDA DE LA HOMOGENEIDAD, LA DOBLE HOJA, LA CÁMARA Y EL AISLAMIENTO TÉRMICO}

Tras la guerra civil, se asiste a un retorno involucionista, a un clasicismo ecléctico de fórmulas neocasticistas sobre las que se pretendió reconsiderar la idea de Estado, presidido paradójica e inevitablemente por una terrible recesión material centrada en la política de reconstrucción de daños y en la apremiante necesidad de viviendas. Aquel racionalismo difuso iniciado en los primeros años treinta, fue sustituido años más tarde por un criterio monumentalista de fibra histórica, representativo de la arquitectura oficial del nuevo régimen. España, por segunda vez en veinticinco años, se vuelve hacia sí misma, hacia su propia historia de forma retórica, con la intención de recuperar en su patrimonio pasado las señas de identidad. Durante la primera década de posguerra, la escasez de recursos materiales disponibles se convirtió a pesar de todo en una propuesta de calidad para un determinado grupo de arquitectos que en el caso de Madrid (F. Asís Cabrero, Fisac, De la Sota, Aburto, Fdez. del Amo), se mostraron de manera individual, enérgicamente inconformistas e interesados por la renovación técnica que convirtiera la obra construida en una consecuencia racional de la verdadera realidad moderna de su tiempo. Desde los organismos estatales de intervención pública, (el INV con sus Planes Nacionales de Vivienda, y la OSH con sus oficinas técnicas de Proyectos) se favorecían las técnicas constructivas más arraigadas al modo tradicional, rechazándose las innovaciones técnicas que se relacionaban con estilos foráneos de vanguardia, se buscaban soluciones rápidas y sencillas que no exigieran una específica preparación de los operarios. La consecuente desaceleración en todos los órdenes constructivos, no implicó, sin embargo, una interrupción en el desarrollo del sistema de doble hoja en los cerramientos de esta primera década entre 1940 y 1949. Su aplicación queda asociada, por un lado, a las tipologías de viviendas de bajo coste en barriadas satélites, realizadas con muros de carga perpendiculares a fachada (entre otras destacan las viviendas para la Dirección General de Arquitectura en el Barrio de Usera de Luis Moya, 1942 $<<$.. las fachadas quedan reducidas a un simple cerramiento ligero con cámaras de aire $>>13$, de $30 \mathrm{~cm}$ de espesor, ejecutadas con doble hoja a base de tabiques extremos de ladrillo, enjarjada la primera hoja al muro de carga transversal estando éste trabado con llaves). Por otra, y heredera de un mismo sistema constructivo, las correspondientes a la actuación de las viviendas Virgen del Pilar, una promoción residencial considerada la más significativa ejecutadas por la Obra Sindical del Hogar, ambicioso proyecto que contemplaba la creación en cuatro fases de 1.220 viviendas, en la que su cuarta fase de 36 viviendas protegidas (Francisco de Asís Cabrero, 1945-48) ${ }^{14}$ se desarrolla con un esquema estructural de muros transversales de ladrillo a cara vista de dos pies, cadenas de atado perimetral realmente interesantes y una solución de doble hoja con cámara en sus fachadas de cierre (a base de medio pie revocado al exterior y tabique interior de ladrillo sencillo). Por otro lado, a las viviendas de clase alta en actuaciones del ensanche, en las que se recupera el desarrollo técnico iniciado de los años treinta a partir de estructuras reticuladas (casi siempre ahora con hormigón armado) en variadas ocasiones haciendo uso de materiales aislantes de corcho, aunque todavía, eso sí, con la presencia de cámaras de gran espesor para regularización de paramentos y ocultamiento de pilares . En este apartado se sitúan distintas obras de $M$. de Cabanyes y Pellón (C/Fernández de la Hoz, 1947), de Eugenio de Aguinaga (C/Alonso Cano c/v C/Viriato, 1947. C/Núñez de Balboa c/v Juan Bravo, 1947), de Luis Gutierrez Soto (C/Juan Bravo c/v C/Velázquez,1940. Plaza del Doctor Marañón, $1944^{15}$. C/Bretón de los Herreros, 1949) o de L.Casanova (C/Príncipe de Vergara c/v C/Juan Bravo, $\left.1947^{16}\right)$. Las viviendas para clases medias, desarrolladas a través de sociedades de gestión inmobiliaria de la Ley de Reforma Tributaria e impulsadas por la Ley de Viviendas Bonificables de 1944, planteaban en su mayoría disposiciones más tradicionales y repetidas a base de muros de carga paralelos a fachada de doble crujía y orientación, con lo que no se facilitaba la aplicación del sistema por capas en sus cerramientos. En este grupo encontramos (aparte de las grandes promociones de las inmobiliarias Urbis, Ceysa, Banús Hermanos, S.Diego...,) las actuaciones residenciales para el Parque Móvil para funcionarios municipales en la C/Bravo Murillo, acogidas a la Ley de Viviendas Protegidas y al Plan Nacional de Vivienda de 1944 (J.Fonseca, Prieto 1943), para el Patronato Municipal de la Vivienda, los bloques lineales de siete plantas de la C/Florestán Aguilar (F.Trigo Seco, 1949) o los bloques de la Colonia S.Cristobal para empleados de la Empresa Municipal de Transportes en el Paseo de la Castellana (S.Zuazo,1949) que siguiendo las mismas pautas que las anteriores $<<$...el espesor de los muros garantiza las condiciones de aislamiento $>>17$.

La década de los años cincuenta sería decisiva por superar la indecisión generalizada y consolidarse el impulso renovador de una nueva generación de arquitectos con una conciencia común de trabajo en equipo (J.A.Corrales, R.Vázquez Molezún, L.Cubillo, R. de la Hoz, J.Cano Lasso, F.J. Sáenz de Oíza, J.M. García de Paredes, J.L. Romany, J.Carvajal, A.Lamela) interesados en fomentar los supuestos funcionalistas y en asentar las bases del Estilo Internacional en cualquiera de sus posibles versiones. De nuevo se reabre el debate sobre la definición del modelo racio- 


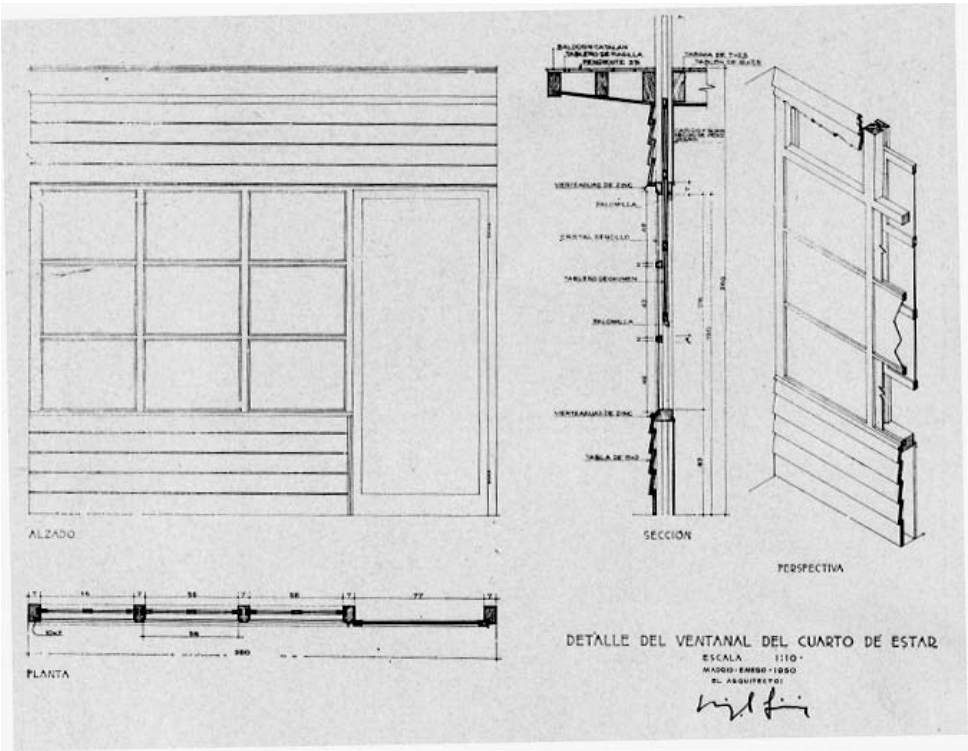

Cerramiento Viviendas en Cadena. M. Fisac, 1949-1950.

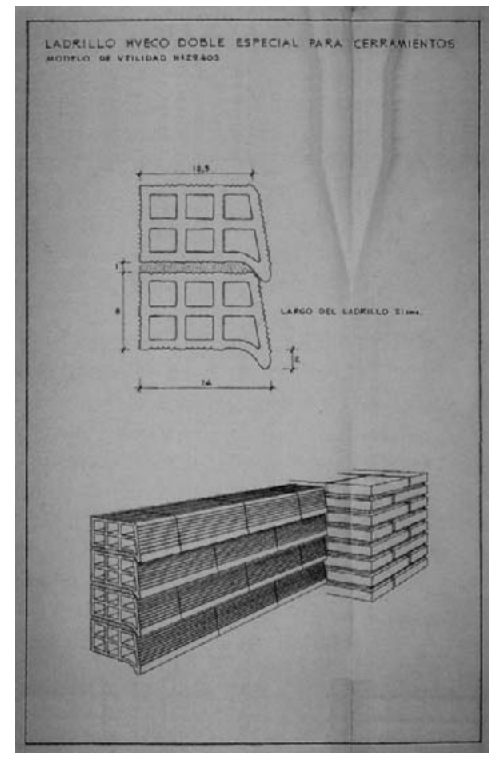

Ladrillo tipo “Goterón”. M. Fisac, 1952. nalista de vivienda mínima de inspiración europea y, con él, una etapa de optimismo desarrollista de signo tecnológico aplicado al experimentalismo constructivo. Se dirigen los esfuerzos en orden a intentar mejorar el todavía acuciante problema de escasez de viviendas, su necesario abaratamiento y aumento productivo situando a la industria en un comprometido servicio de progreso social. Se invalidaban los métodos tradicionales para la construcción de alojamientos y se fomentaron los criterios alternativos de prefabricación, normalización dimensional, seriación, coordinación, organización del trabajo, mecanización y modulación, como exigencias para una obligada transformación y todo ello a pesar del momento de crisis generalizado del sector. Al mismo tiempo, se vuelve la mirada a la arquitectura internacional de prototipos, rompiendo la tendencia anterior más vernácula. Lucio Costa recuerda la importancia del progreso técnico que permite entender que: $<<$ pared y soporte representan hoy dos funciones totalmente distintas por lo que se refiere al material con que están construidas, como a su espesor. Fabricados los primeros con materiales ligeros...se deslizan junto a los soportes impasibles $>>18$. Siguiendo esta línea, y como primera aportación de calidad, en 1949 se convoca por el Colegio de Arquitectos de Madrid, un concurso para alojamiento colectivo, la propuesta ganadora de Miguel Fisac representa una apuesta firme por los criterios de coordinación material e integración constructiva. Solución seriada a base de muros resistentes de un pie perpendiculares a fachada, con doble orientación y cerramiento con disposición ligera autoportante con cámara y doble hoja, adaptable a las futuras necesidades de ampliación de sus usuarios. Se trata, por fin, de uno de los primeros casos en los que la definición material se ajusta a su exigencia funcional, expresión final de la forma construida. Permite además anticipar en su intención, lo que significaría tres años más tarde la aparición de su famosa pieza cerámica a la que nos referiremos más adelante.

Esta variedad de sistemas constructivos característicos del cambio de década, se acompaña con la aparición de los nuevos materiales aislantes que ofrece la industria y la difusión de artículos técnicos sobre sus criterios y ventajas de aplicación. De esta manera y gracias a las espumas y fibras de vidrio, serrín de madera, vidrio celular... el sistema de doble hoja empieza realmente a ser competitivo económicamente, reduciendo su coste en cinco o seis veces con respecto a la utilización de las planchas de corcho. En 1950, el Ingeniero Bossut, además, denuncia por fín la falta de eficacia térmica de las grandes cámaras de aire en los cerramientos y así afirma: $<<$ No puede negarse que los recintos de aire constituyen excelentes medios aislantes, puesto que el aire es el mejor aislante; pero los que parten de esta base para justificar la eficacia de la cámara olvidan que para ello la condición imprescindible es que las dimensiones de los recintos de aire sean lo suficientemente reducidos para que en ellos no se produzcan corrientes de convección,....El conocimiento de lo anterior ha llevado a prescindir por completo de las cámaras de aire a muchos arquitectos y constructores, sustituyéndolas con materiales aislantes de alta eficacia térmica; esta es la única solución racional y eficaz al problema del aislamiento térmico $>{ }^{19}$. Describe también un ejemplo de edificio construido con cámara de $8 \mathrm{~cm}$ frente a otro aislado con $5 \mathrm{~cm}$ de fibra de vidrio, el ahorro energético supone un $25-30 \%$ del edificio, se pasa de un coeficiente de transmisión térmica $\mathrm{K}$ de 0,905 a otro de $0,38 \mathrm{Kcal} / \mathrm{hm}^{2}{ }^{\circ} \mathrm{C}$.

Surgen también nuevos productos cerámicos aplicados al nuevo concepto constructivo de cerramiento, generalmente 


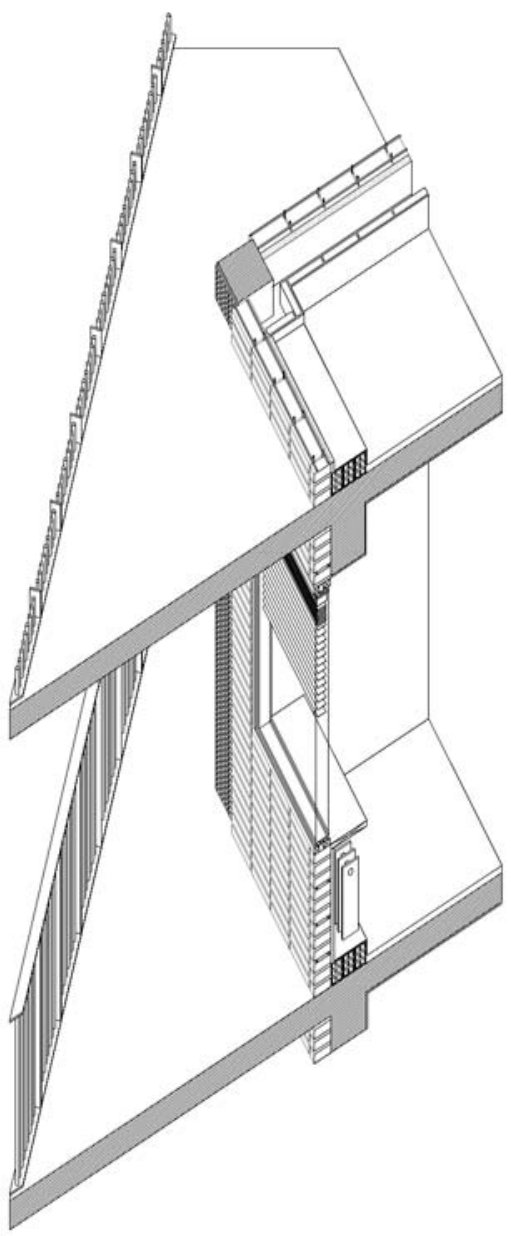

Colegio Mayor Sto.Tomás de Aquino. Padres Dominicos. Rafael de la Hoz, José María García de Paredes, 1953-57.

para aliviar la carga permanente a las vigas de fachada así como simplificar el proceso de puesta en obra del sistema y mejorar la resistencia térmica del elemento. Este es el caso del Ladrillo tipo Goterón o Pestaña patentado por Fisac en 1952, que desde su primera utilización en el edificio del Instituto de Microbiología Ramón y Cajal de Madrid (1949-1956) ha sido empleado en otros muchos casos no sólo de su autor (Residencia de los Padres Dominicos en Alcobendas, 1955-1956), sino por otros arquitectos como L. Gutiérrez Soto, A. de la Sota, Cassinello, M. de Cabanyes en Madrid o M.Marín Rodríguez-Rivas en Gijón. Su disposición contemplaba la posibilidad de incorporar una manta Vitrofib en el trasdós.

Ante la posibilidad del uso de los nuevos materiales de cerramiento que planteaban una nueva relación física del mismo con la estructura portante, y al poder garantizarse el suficiente comportamiento térmico favorable, es viable reducir al máximo el espesor construido, siendo inferior en la mayoría de los casos a la planta de los pilares, quedando de esta manera el cerramiento encastrado entre los

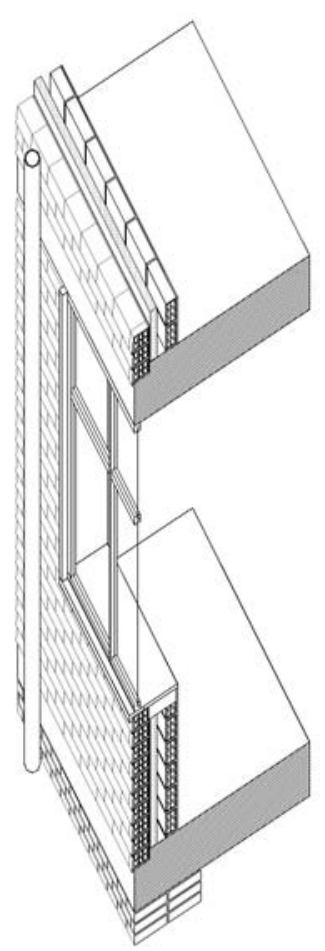

Residencia Padres Dominicos. Alcobendas. Miguel Fisac, 1955-1956.

vanos de la estructura principal. La exhibición de este avance técnico trajo consigo el desarrollo compositivo de un tipo de fachadas muy características entre 1955 y 1960 aproximadamente, y a las que he convenido en denominar: Fachadas Encintadas. Acusan la función de puro cerramiento de los muros exteriores, la mayoría llevan material aislante e implican un culto a la sinceridad constructiva con un alcance tal en lo compositivo arquitectónico que la práctica mayoría de los arquitectos de calidad de la época no pudieron sustraerse a una moda que significaba modernidad técnica. Entre los numerosísimos ejemplos repartidos por toda la ciudad y sin distinguir entre viviendas de categoría elevada o bajo presupuesto, podemos señalar: Hotel Consular de Apartamentos ( $J$. Núñez Mera, 1952), Viviendas Experimentales (E. Sánchez Lozano y J. L. Romany, 1956/57), Viviendas sociales Grupo S. Nicolás (F. Asís Cabrero, 1954/55), Avda. Islas Filipinas $\mathrm{n}^{\circ} 42$ (A. Lamela, 1956), Edificio Viviendas Experimentales (I. Alvarez Castelao, 1956), Edificio Viviendas C/Concha Espina (Muñoz Monasterio, 1956), Tipología de torre. Poblado dirigido de Cañorroto 


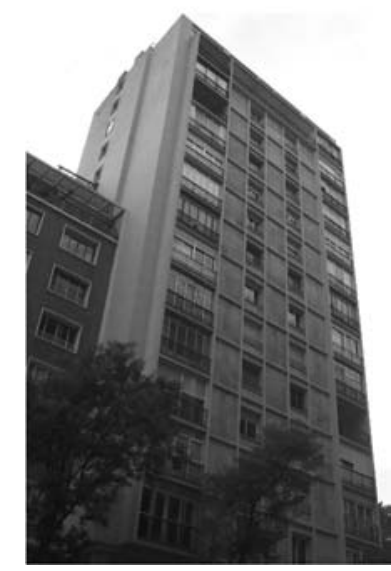

Edificio Viviendas. C/ Concha Espina Arquitecto: Muñoz Monasterio, 1956.

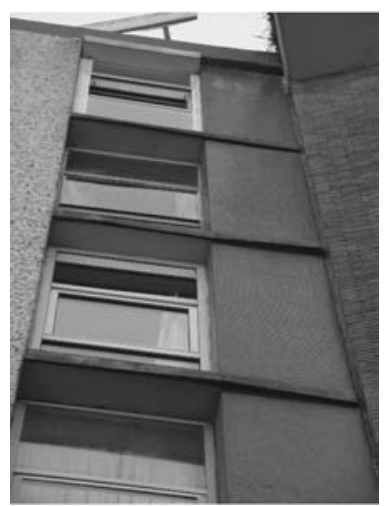

Avda/Islas Filipinas, $n^{\circ} 42$ Arquitecto: A. Lamela, 1956

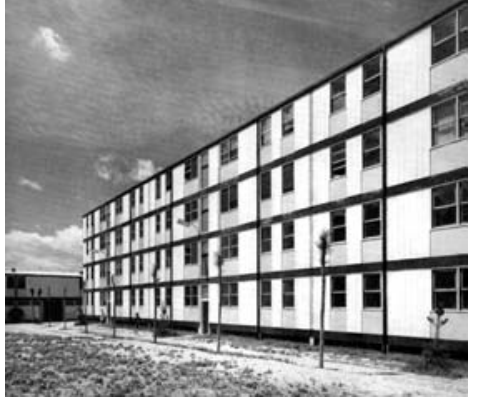

Viviendas Experimentales. Arquitectos: E. Sánchez Lozano y J. L. Romany, 1956/57.

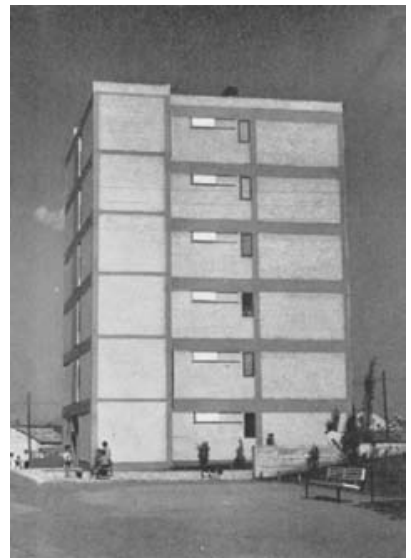

Poblado dirigido de Cañorroto. Arquitectos: A. Vázquez de Castro y J. L. Íñiguez de Onzoño, 1957/59.

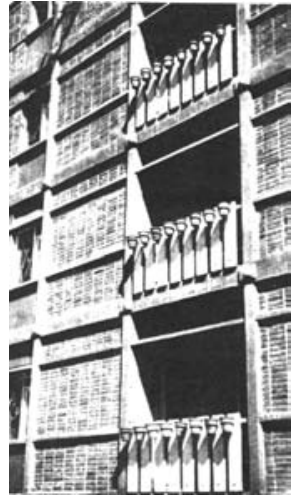

Edificio Viviendas Experimentales. Arquitecto: I. Alvarez Castelao, 1956.

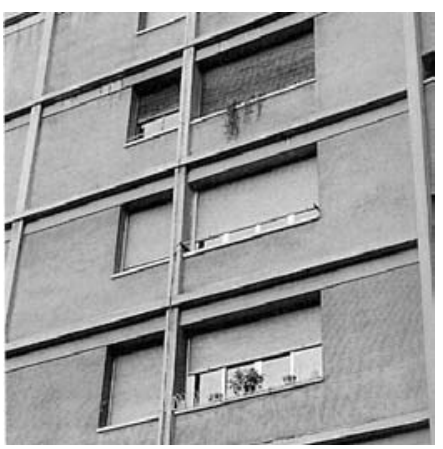

Edificio para empleados de Laboratorios ALTER. M. Fisac, 1957. Arquitecto: M. Fisac, 1957.
(A. Vázquez de Castro y J. L. Iñiguez de Onzoño, 1957/ 59), Torre en Plaza de Cristo Rey. (F. J.Carvajal y $R$. García Lozano, 1956) Edificio para empleados Laboratorios ALTER (M. Fisac, 1957), En este momento es posible realizar una primera clasificación de los cerramientos de doble hoja en el análisis de la arquitectura madrileña, según la relación con la estructura y espesores relativos de hojas. En primer lugar, un tipo pesado de gran espesor (40 $\mathrm{cm} \leq \mathrm{e} \leq 65 \mathrm{~cm}$ ) caracterizado por una primera hoja gruesa no inserta ni en planta ni en sección, con generosa cámara de aire con o sin aislamiento y una segunda hoja de tabique. Propia de una categoría residencial de lujo y para edificios de más de siete alturas, la encontramos por ejemplo en el edificio de viviendas del Paseo del pintor Rosales (L.Gutierrez Soto, 1952), en las de la Plaza Luca de Tena (Moreno Barberá, 1955), en el Hotel Memfis de la Gran Vía (M. de Cabanyes, 1952), o en la torre del Paseo Moret (J. de Zavala, 1954). En segundo lugar, de peso y espesor medio $(30 \mathrm{~cm} \leq \mathrm{e} \leq 40 \mathrm{~cm})$, con hoja exterior delgada y preferentemente inserta, con o sin cámara, con o sin aislamiento, origen del modelo denominado hoy convencional, con acusados problemas de puentes térmicos, apareciendo además el riesgo de pérdida de soporte de su primera hoja. El Hotel Consular (Núñez Mera, 1951), el edificio de viviendas en la C/Jorge Juan (L.Gutierrez Soto, 1952), Colegio Mayor Sto.Tomás de Aquino.padres Dominicos. (Rafael de la Hoz, José María García de Paredes, 1953-57), del Paseo de la Habana (E.Población, 1958) o el de la C/O'Donell (J. M. Garma, 1956), son ejemplos de este tipo de cerramiento, en los que $<<$ la construcción es la ya clásica en Madrid. Estructura de Hormigón armado, forjados de cerámica armada y muros de ladrillo hueco doble formando cámaras de aire, plaqueta de Alcalá y piedra artificial en jambas, impostas y corni$s a s>>20$. Y, en tercer lugar, un tipo ligero y reducido $(20 \mathrm{~cm} \leq \mathrm{e} \leq 30 \mathrm{~cm})$ con hoja exterior delgada y pasante, sin espacio libre disponible de cámara y con material aislante. En ellos, es inevitable la presencia hacia el interior de mochetas de pilares como el edificio de la C/ Diego de León (F. G. Mercadal y R. Aníbal Alvarez, 1948), o el ejemplo interesante de mínimo espesor del Hotel Tirol en la C/Marqués de Urquijo (S. Rey Pedreira, 1955) en el que 


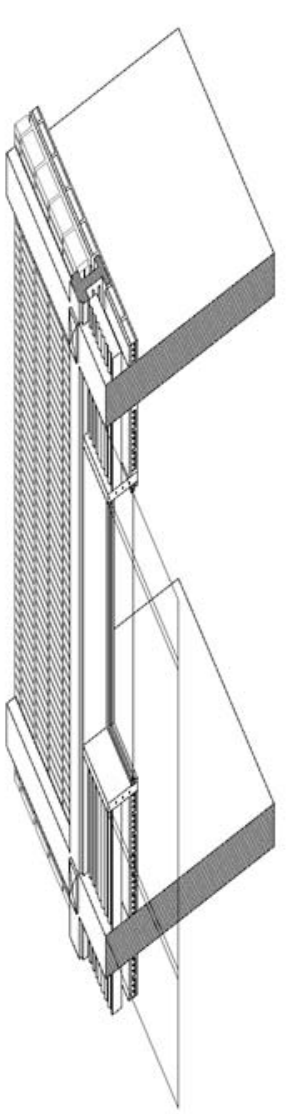

Viviendas Experimentales. Ignacio Alvarez Castelao, 1956-58.

$<<$ toda la estructura es de hormigón armado por pilares situados en los límites del solar, excepto en la fachada, que se retiran 1,25 $m$ para obtener la mayor diafanidad exterior $>>21$.

Finalmente, para concluir este recorrido por la implantación y desarrollo de los sistemas de doble hoja en los cerramientos de fábrica de la arquitectura madrileña durante el siglo XX, hay que referirse de manera obligada a la investigación sobre el modelo de vivienda modesta entorno a lo que significó por una parte, el Concurso de Viviendas Experimentales de 1956 y por otra, el desarrollo de las unidades vecinales de los Poblados.

El Concurso, convocado por el INV, dirigido por Valero Bermejo, para las 866 unidades finalmente realizadas, persigue superar los condicionantes de escasez de recursos constructivos, que obligaban a la utilización de métodos tradicionales, por otros nuevos planteamientos industrializables alternativos que permitieran obtener una mejora de calidad y coste en las necesarias viviendas económicas. Ello aplicable para la fórmula innovadora de arquitecto y empresa sobre un mismo tipo de bloque de 24 viviendas, de $80 \mathrm{~m}^{2}$ como máximo, de $\mathrm{PB}+3$ o unifamiliares en hilera. La importancia de este concurso reside en la enorme variedad de soluciones planteadas, que sirvieron de repertorio y experiencia pionera constructiva para posteriores actuaciones. El criterio de valoración de las propuestas por parte del jurado contemplaba un $20 \%$ del total para el sistema constructivo empleado, repartido uniformemente entre las soluciones particulares de estructura resistente, cubierta, aislamiento térmico y otras cuestiones varias ${ }^{22}$. En las tipologías con estructura tradicional y cerramientos de fábrica, destaca la propuesta de Fernando Cassinello asociado a la empresa constructora Calomina y Serrano, $<<$ el cerramiento se soluciona también con material cerámico, disponiendo al exterior una primera fábrica de medio pie de "ladrillo de ceja”, y un tabique posterior, después de enfoscar y dejar intermedio una cámara de aire de $4 \mathrm{~cm}$ de espesor $>>>^{23}$. Los casos en los que se plantean estructuras mixtas, como el presentado por Carlos de Miguel, el cerramiento resistente se reduce a una única hoja de un pie de espesor como plementería de marcos de carpinterías de hormigón vibrado que funcionan además como miras de puesta en obra. Una de las soluciones más singulares, se consigue con estructura reticular completa, a partir de un sistema integral de elementos prefabricados y modulados tipo "mit". La empresa constructora Asturiana, S. A., junto con Ignacio Alvarez de Castelao, proponen, para ello, una serie de retículas armadas bidireccionales como estructura horizontal, piezas verticales con armadura de enlace en obra, moduladas según $35 \times 35 \mathrm{~cm}$ para formación de huecos, arriostradas a su vez por piezas horizontales entre montantes principales de manera que pudieran timpanizarse posteriormente con piezas de fábrica, en este caso con ladrillos dispuestos con llagas continuas, o placas prefabricadas de antepechos y dinteles. Los $25 \mathrm{~cm}$ de espesor resultante, se obtiene además, disponiendo una segunda hoja interior de tabique sencillo y cámara con aislamiento incorporado.

A pesar del indiscutible interés en racionalizar los procesos de normalización constructiva del concurso, supuso tan sólo una revisión mejorada de variantes tradicionales, no representó un abaratamiento de recursos y finalmente tampoco alcanzó demasiada repercusión social. Se puso de manifiesto las precarias posibilidades reales de aquella industria carente todavía de los necesarios controles de producción.

Por su parte, la construcción de los Poblados, promovidos por la OSH, financiados por el INV, gestionados desde la COUM y enmarcados en la Ley de Vivienda de Renta Limitada de 1954 en su Grupo II del Régimen de Protección, no se basó nunca en una gran experimentación técnica de recursos materiales, sino en soluciones de una máxima simplicidad, aunque demostró su interés por las cuestiones de salubridad y confortabilidad ambiental. En los Poblados de Absorción, en los que era más necesaria si cabe la simplificación extrema de sus soluciones, se ensaya un cerramiento no cargado con doble hoja, cuyo espe- 
sor final se encuentra condicionado por la pieza de retorno de dimensión de 1 pie, al enlazar la primera hoja de medio pie con la segunda de tabique sencillo en los encuentros con los huecos. La cámara de aire resultante es del orden de $7 \mathrm{~cm}$. Tal solución la encontramos con absoluta claridad en el Poblado B de Fuencarral (A. de la Sota, 1954-56). Por tanto, $y$, tras un análisis ganeral, se puede afirmar que las soluciones constructivas de los cerramientos de este tipo de viviendas sociales, reguladas o subvencionadas, desarrollan precariamente las composiciones de doble hoja sin que exista un criterio fijo de aplicación para hacerlo de un modo u otro. Los condicionantes materiales obligan a minimizar los recursos empleados y son varios los ejemplos en los que se puede observar la intención del arquitecto en dirigir un tipo de solución en función de los factores y agentes externos. En edificios de baja altura, normalmente prevalece el papel resistente del cerramiento y, la mayoría de las veces, se simplificaría la solución con una única hoja gruesa de un pie. En los de mayor altura, el cerramiento se convierte en una cuestión de plementería discontinua a base de obtener el mayor aislamiento mediante la combinación de las dos hojas, la primera de medio pie y la segunda un tabique sencillo con cámara de aire entre los elementos sustentantes. En algunos casos, se simplifica la solución disponiendo una hoja exterior de medio pie no resistente doblada al interior con un tabique sin cámara.

De todo el repertorio de cerramientos analizados en estos asentamientos y núcleos satélites de viviendas, destacan por su complejidad, audacia y buena conservación dos casos concretos. El primero en el Poblado Dirigido de Fuencarral (J. L.Romany, 1958-1960), formado por una primera hoja de arriostramiento de medio pie sentada a tabla de ladrillo hueco sencillo, $3 \mathrm{~cm}$ de aislamiento térmico de fibra de vidrio sobre enfoscado de trasdós y tabique sencillo la hoja interior. El resultado es un cerramiento de $25 \mathrm{~cm}$ de espesor con un coeficiente de transmisión $\mathrm{K}$ de $0,614 \mathrm{Kcal} / \mathrm{hm}^{2}{ }^{\circ} \mathrm{C}$. El segundo, en el Poblado Dirigido de Almendrales (Carvajal, Corrales, $G^{a}$. de Paredes y Vázquez Molezún, Primera Fase, 1959), con una estructura principal de muros de carga interiores, resuelve el cerramiento con una solución de entramado a partir de una primera hoja de medio pie al exterior atada cada cuatro hiladas con perpiaños a la segunda hoja interior de tabique sencillo, de nuevo el resultado es un cerramiento de $25 \mathrm{~cm}$ de espesor pero ahora el coeficiente $\mathrm{K}$ sube hasta $1,389 \mathrm{Kcal} / \mathrm{hm}^{2}{ }^{\circ} \mathrm{C}$.

Por entonces y en consecuencia, la realidad constructiva consideraba globalmente la tendencia y asimilación generalizable del nuevo tipo de cerramiento, que asume adoptar en la mayoría de los casos una solución común, que ya no representaría para los arquitectos madrileños ninguna novedad, ni de momento, preocupación técnica o de diseño. Tal apreciación sobre la estandarización conseguida del sistema queda reflejada en la definición que rea-

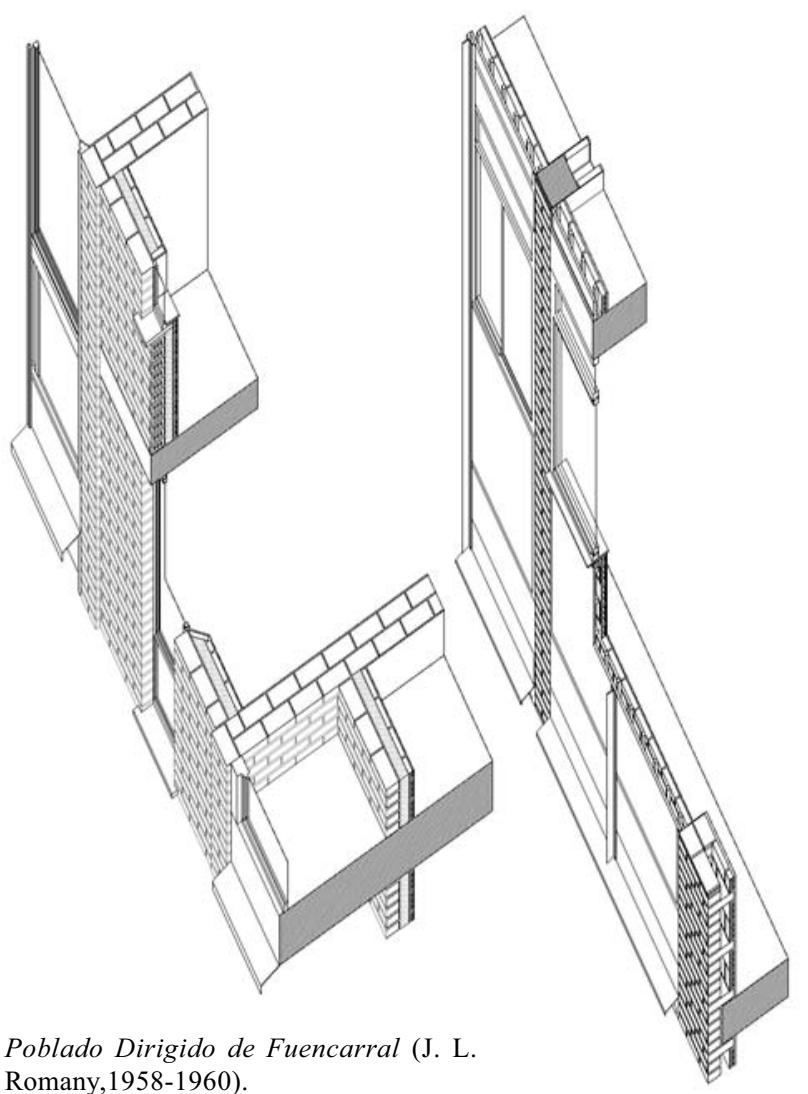

Poblado Dirigido de Almendrales (Carvajal, Corrales, $\mathrm{G}^{\mathrm{a}}$. de Paredes y Vázquez Molezún, Primera Fase, 1959).

liza Julio Cano Lasso para su edificio de la C/Espalter (1956-1959) cuando afirma: $<<$ La estructura se hizo de hormigón armado, porque en aquél tiempo el coste de las estructuras metálicas era un 60 por ciento mayor que el de las de hormigón... Los muros exteriores no tienen en ningún caso función resistente y su función es de aislamiento. Por ello se han constituido con medio pie de ladrillo de tejar, enfoscado e impermeabilizado por su cara interior; revestimiento de fibra de vidrio, cámara de aire $y$ tabique $>>{ }^{24}$.

Los aspectos normativos generales referidos a la construcción de viviendas y sus cerramientos, son determinantes como factores de influencia en el desarrollo del sistema de doble hoja. El Reglamento Técnico de la Ley de Protección de Vivienda se aprueba el 18 de septiembre de 1939 , y con él se tipifican las ordenanzas generales constructivas de aplicación y los modelos característicos que habrían de cumplir las viviendas protegidas bajo el amparo del Estado, que darían lugar al desarrollo de una normativa específica en la que se enmarcó la práctica generalizada de los asentamientos residenciales como respuesta al aumento de población en la ciudad. Será el Reglamento de Régimen Interior del INV del 29 de enero de 1941, y bajo la dirección de Benjumea Burin el que definirá las 
condiciones mínimas para las viviendas protegidas consideradas en el régimen legislativo. Significa, por primera vez, desde los organismos estatales y con relación a lo definido en anteriores textos normativos, un avance importante de exigencia en la precisión y cuantificación objetiva de los datos técnicos presentes en el proyecto. Puede considerarse un factor decisivo en la especialización material del cerramiento, fijándose además las zonas climáticas de aplicación con respecto a límites máximos aceptables de conductividad entre 1,2 y $1,4 \mathrm{Kcal} / \mathrm{hm}^{2}{ }^{\circ} \mathrm{C}$, así como al establecer la proporción de huecos en fachada no superior a los $2 / 5$ del muro. Por primera vez se dejaba abierta la posibilidad de proponer, siempre que fuera económicamente viable, soluciones avanzadas para racionalizar y justificar el cumplimiento de las establecidas condiciones mínimas de calidad marcadas por la normativa. La siguiente Norma fundamental entra en vigor con la Ley de Viviendas de Renta Limitada el 15 de julio de 1954, con su inmediato reglamento de Ordenanzas técnicas y normas constructivas el 12 de julio de 1955, derogando todos los anteriores textos vigentes de aplicación, mejorando y completando ciertas cuestiones tratadas con ambigüedad en los existentes hasta la fecha. En el marco de esta ley se desarrollarían las actuaciones más representativas en materia de alojamiento social bajo la dirección de los organismos públicos del régimen, el INV, la OSH y la
COUM, como fueron los asentamientos de los Poblados Dirigidos. En la Ordenanza $8^{\text {a }}$ de sus Instrucciones Complementarias se obliga a la cámara de aire en los muros, llegando definitivamente a la regulación normativa del sistema de doble hoja con alcance nacional, aunque esto sucediera treinta años más tarde que su reglamentación en Inglaterra a cargo del Ministerio de la Salud. El cerramiento puede definirse ahora según sus propios parámetros, viéndose afectado por un proceso de aligeramiento continuo de acuerdo al ideal de economía y eficacia. Su progresiva simplificación dentro de una audacia constructiva general, ha dado lugar, a lo largo del final del siglo XX, a una situación extremadamente delicada del tipo de cerramiento analizado, que hace necesario sin duda, pensar definitivamente en un nuevo modelo de garantía para el siglo XXI.

\section{AGRADECIMIENTOS}

El autor del artículo agradece al Profesor Josep $\mathrm{M}^{\mathrm{a}}$ Adell, la dirección de su Tesis Doctoral titulada: "Origen e influencia constructiva del sistema de muro de doble hoja en la historia y composición de obras de fábrica de cerramientos en la arquitectura contemporánea residencial madrileña entre los años 1910 a 1958”, evaluada con sobresaliente "cum laudem", siendo este artículo un pequeño extracto de la misma.
${ }^{1}$ Así, en su Art. 58, y con relación a los elementos de cierre se puede leer: $<<$ Los cimientos y muros hasta $1 \mathrm{~m}$ de altura han de construirse de modo que resulten protegidos contra la humedad del suelo...Los muros exteriores y las cubiertas deberán tener las debidas dimensiones para garantizar su solidez y habrán de proteger suficientemente el interior contra las variaciones atmosféricas de humedad y temperatura $>>$. En su Art. 94 se refiere a la necesidad de emplear los conceptos básicos de sencillez constructiva a favor de la economía general del sistema y afectando a las decisiones de acabados, sabiendo que los detalles constructivos finales serían $<<$ de la iniciativa de los arquitectos y peritos que proyecten las casas, los cuales adoptarán, en cada caso, los procedimientos más convenientes dentro de la economía. Ésta se obtendrá empleando fábricas y entramados de sencilla construcción y aprovechando hábilmente los materiales que brinde la localidad; pero no ha de imponerse la economía hasta el punto de que carezca la obra de las garantías de solidez y duración compatible con la reducción razonable de los gastos de construcción y mantenimiento, ni ha de olvidarse tampoco que, para los efectos sociales, el concepto de casa barata no puede desligarse del de casa higiénica $>>$.

${ }^{2}$ Durante la década de 1920, se implanta de forma reglada la enseñanza del Hormigón armado en la Escuela de Madrid. Modesto López Otero, como director de la Escuela, en 1928 decidió impulsar su conocimiento invitando a E. Torroja a impartir conferencias sobre la nueva técnica.

${ }^{3}$ Fernando García Mercadal escribiría al respecto de la Exposición celebrada en la Colonia de Weissenhoff de Stutgart en 1927: $<<$ El arte por el arte ya no tendrá ninguna significación. Sólo de una arquitectura técnica podrá hablarse en adelante $>>$.
${ }^{4}$ Salvador, Amós. $<<$ Sobre la vivienda mínima $>>$ Arquitectura . Año XI, n ${ }^{\circ} 125$, oct.1929, pp. 355-362.

${ }^{5}$ A.C. $\mathrm{n}^{\mathrm{o}} 1,1931$.

${ }^{6}$ F. González, La Construcción Moderna no ${ }^{\circ}$. En él todavía se echan en falta explicaciones técnicas sobre su rendimiento.

7 Mariano Bastos, $<<$ Aislamientos térmicos $>>$ Arquitectura $\mathrm{n}^{\circ}$ 89, pp. 359.

${ }^{8}$ Rafael Bergamín, $<<$ Casa del Marqués de Villora $>>$. Arquitectura, año X, n 113, Septiembre 1928. pp. 282-288.

${ }^{9}$ Cabanyes, Manuel de $<<$ Bloque de dos casas con viviendas de tipo burgués $>>$. Nuevas Formas, no 8, 1935-1936, pp. 396-399 ${ }^{10}$ Ibídem, pp. 396-399.

${ }^{11}$ Se puede valorar la aportación que en este sentido pudo realizar Miguel Fleischer, un joven arquitecto alemán que por esas fechas colabora en el estudio de Zuazo, participando en el desarrollo final de los últimos detalles, como dice Zuazo: $<<$ Cuando Fleischer llegó a mi estudio, el proyecto estaba decidido. El fue sólo un buen ayudante que resolvió algunos detalles $>>$. Carlos Flores, Entrevista a Secundino Zuazo, en revista Hogar y Arquitectura, $\mathrm{n}^{\mathrm{0}} 75,1968$.

${ }^{12}$ Gabriel de la Torriente. $<<$ Casa de Campo en el Escorial $>>$. Nuevas Formas, año I, nº 6,1935.

${ }_{13}$ Moya, Luis. $<<$ Casas abovedadas en el Barrio de Usera $>>$. Revista Nacional de Arquitectura, año II, n ${ }^{\circ}$ 14, febrero 1943. pp. 52-57.

${ }_{14}$ Cabrero, Francisco de Asís, $<<$ Viviendas económicas en Madrid $\gg$. Informes de la Construcción, año VII, abril 1955, $\mathrm{n}^{\mathrm{o}} 70$.

${ }^{15}<<$ entramado metálico,..., el resto de la fachada un pie con cámara de aire y tabique,...planchas de corcho dentro de las 
cámaras de aire $>>$ Gutierrez Soto, Luis. $<<$ Casa de Pisos en la Avenida del Generalísimo, ${ }^{0}$ 59>>Revista Nacional de Arquitectura, no 64, año VII, abril 1947, pp. 132-142.

${ }^{16}<<$ la estructura es de hormigón armado, habiéndose cerrado los vanos con fábrica de ladrillo hueco doble, dejando cámaras de aire a fin de que el coeficiente de conductibilidad en muros sea, cuando menos de 1,4>> L. Casanova $<<$ Casa de pisos en Madrid $>>$ Revista Nacional de Arquitectura, $\mathrm{n}^{\circ}$ 65, año VII, mayo 1947, pp. 179-182.

${ }^{17}$ Zuazo,Secundino: $<<$ Viviendas económicas $>>$.Informes de la Construcción, año VII, mayo 1954. Destaca igualmente en el edificio como solución interesante, la dispuesta en el arranque de la solera de planta baja separada del terreno con una cámara de aire ventilada, formada por tabiquillos, en las fachadas de los bloques para evitar así humedades en el interior de viviendas. ${ }^{18}$ Costa, Lucio. $<<$ Razones de una nueva arquitectura $>>$. Informes de la Construcción, $\mathrm{n}^{\circ}$ 9, septiembre 1949.
${ }^{19} \mathrm{~J}$. Bossut. $<<$ Las cámaras de aire en la construcción moderna $>>$ Revista Nacional de Arquitectura, 1950.

${ }^{20}$ José María Garma, $<<$ Casas de vecindad en la C/O'Donell $>>$ Revista Nacional de Arquitectura, ${ }^{\circ}$ 176-177, AgostoSeptiembre,1956,pp.33-35.

${ }^{21}$ Rey Pedreira, Santiago. $<<$ Hotel Tirol en Madrid $>>$ Revista Nacional de Arquitectura, $\mathrm{n}^{\circ}$ 178, año XVI, 1956. pp.40-42.

${ }^{22} \mathrm{El}$ criterio de valoración sobre el rendimiento del trabajo y maquinaria quedaba fijado en un $35 \%$ del total, los aspectos compositivos y funcionales de planta y alzado un $25 \%$ y la calidad del sistema constructivo y la ejecución de carpinterías e instalaciones el $40 \%$ restante.

${ }^{23}$ Cassinello, Fernando. $<<$ Viviendas Experimentales $>>$. Revista Nacional de Arquitectura, año XVIII, n 193 , enero 1958, pp. 10-12.

${ }^{24}$ Cano Lasso,Julio. $<<$ Viviendas en Madrid $>>$. Arquitectura, año $3, n^{\circ} 34$, octubre 1961 , pp. 7-11 